\title{
Application of competition teaching method in basketball teaching
}

\author{
Youbo Ge \\ Jingzhou Institute of Technology, Jingzhou Hubei, 434020, China
}

Keywords: Basketball, Competition teaching method, Techniques and tactics training.

\begin{abstract}
Basketball teaching is an important component of physical education, which can get a lot of people participated and enjoys high popularity, thus it has been well received and favored among learners. However, due to old-fashioned teaching methods, and complicated teaching contents, teachers have focused on help students obtain technical key points so that they spend all time in repeated training and the teaching effect is not satisfactory. Thus, it is necessary to make improvement so as to achieve the fixed teaching goals through introducing competition teaching methods. This article has elaborated the important role of competition teaching method in basketball teaching, discussed specific strategies of applying competition teaching method in basketball teaching, and also proposed some problems need attention when applying competition teaching method in basketball teaching.
\end{abstract}

\section{Introduction}

Previous basketball teaching just emphasized the change of techniques but deviated with students' actual expectations, which prevented the integrity of basketball teaching from being guaranteed and restricted learners' learning enthusiasm, thus it cannot adapt to the development requirements of nowadays physical education. Competition teaching method is to carry out teaching activities with teacher oriented by using the method of competition games on learners. The competition mentioned here is not the athletics competition in traditional meaning. With very abundant meaning, it can help learners to study and experience the techniques and tactics of basketball game in confrontation and game, and improve personal basketball application ability while fully having fun. With the continuous development of basketball techniques and tactics, basketball teaching method has changed from the single technique training to a diversified teaching so that competition teaching method is playing a more and more important role.

\section{The significance of applying competition teaching method in basketball teaching}

Firstly, it can improve learners' learning initiative. During basketball learning process, learners should establish the learning model and have a strong mental awareness of self-confidence. In this case, application of competition can satisfy their mental demands and help them to develop their learning passion on the basis of satisfying their own expression and understanding emotional needs. After investigating according to rules of physical education, we find that improving athletic ability requires for the passion of initiative learning and requires for training with corresponding quality and quantity. Thus, to break through the teaching method, it is necessary to reasonably use competition method to promote students to have stronger learning interest and establish good habit of self-training.

Secondly, it can improve students' basketball actual combat capacity. In basketball teaching, it is common that technical training and competition ae disjointed with each other. When conducting basketball teaching, students should fully apply techniques they have learned in competitions after obtaining essentials of action, and keep consolidating and perfecting their own techniques so as to combine with practical application and substantially shorten the time difference between their learning and application. Competition teaching method can also help students to closely relate their 
practice purpose with the ultimate goal of each action so as to fully improve students' actual combat capability.

Thirdly, it can improve learners' theoretical knowledge. According to the present situation, basketball theoretical knowledge teaching is the poorest. Thus, it is necessary to combine practice with theory and substantially change the incorrect cognition of ignoring theories. As basketball theoretical knowledge learning is very boring, it requires PE teachers to be flexible in teaching methods so as to make study vivid and interesting. Theoretical teaching should also focus on vividness. Analyze and research data of domestic and foreign important competitions to supplement the deficiencies of obsolescent teaching materials. It is also possible to discuss some universal problems occurred in competitions at class based on students' practical condition as the guidance of theory teaching through the connection between theory and practice.

Fourthly, it can cultivate learners' interpersonal relationship. Training of basketball learning mainly refers to free combination among students. The connection has establish an extremely particular social group so that the communication seems directly and it can be promoted in a very good atmosphere. In such an environment, students can easily eliminate personal tense feeling and substantially reduce loneness, and obtain various information from the outside world based on basketball training. Students can improve their teamwork awareness through basketball learning and obtain self-recognition. Application of the role attempt in competition teaching method can play a significant promotion effect to develop learners' self-awareness. Through establishing harmonious interpersonal relationship and applying good mental habits when participating in competition teaching can lay foundation for students to successfully undertake some social roles after getting employed in the future.

\section{Specific strategies of applying competition teaching method}

Firstly, PE teachers can conduct reasonable origination and distribution for learners' learning activities. The teaching purpose of competition teaching method is to achieve the effect of getting twofold results with half the effort, which requires for effective organization of basketball competitions based on teaching contents. For example, it is possible to organize various ball handling, passing and shooting in basic movement training, or organize halves or full court competition in tactics and competition rules teaching. In specific basketball teaching, it is necessary to conduct basic techniques, basic tactics and practical competition, and other methods of alternative teaching content education so as to help learners understand the purpose of learning techniques is for specific application in real competitions. The allocation of teaching time should be scientific and reasonable. The competition time can reach $60 \%$, and the time for other activities can reach $30 \%$, but the rest $10 \%$ should be used as the time for quality training. According to this proportion, allocation can realize the maximization of time utilization and it can help students to solidify their own basketball basic knowledge and master relevant essentials of movements. Basketball teaching should be conducted step by step to continuously improve learners' athletic ability. Otherwise, learners' initiative shall be restricted and it will prevent the basketball competition teaching to be smoothly conducted

Secondly, when applying competition teaching method, it is necessary to start form the practical condition based on students' specific situation. Teachers should make appropriate arrangement of competition teaching method based on students' physical quality condition and teaching plan design, and clarify the object of teaching should be the whole learners, try as far as possible to make the competition contents and forms to be comprehensive by considering all students' substantial benefits. The arrangement of completion should be diversified as far as possible and focus on the form innovation such as the distinctive design of student quantity, gender, and rules, and multiple change of venues. By doing so, it is possible to create more experiencing chances for students and substantially improve students' attraction and participation. Meanwhile, when applying this teaching method, it is necessary to pay great attention to the conclusion in the final stage. Teachers should observe learners' basketball completion and quickly point out problems displayed during their performance and give enough recognition for their outstanding performance. Students can correct 
their problems through teachers' conclusion and problem detection. This is the real significance of competition teaching method.

Thirdly, apply point system in basketball completion to promote training. In basketball competitions, point system is usually used, with team as the competition unit to explore and break through technique difficulties by all team members, and analyze tactical cooperation so as to achieve the goal of mutual progress. Application of this method is a kind of experiential teaching conducted with the learner as the teaching subject to improve learners' teamwork awareness and mutual communication for the purpose of creating a more harmonious learning environment. Students can be divided into several teams for mutual confrontation between different teams. Different point systems can be used in different stages so that learners can establish specific tactics of team combat according to competition rules. By doing so, the point system can help students to develop a huge momentum of continuous learning and to improve their interest of participating into basketball games.

Fourthly, actively innovate specific forms of basketball completion teaching. The most important contents of basketball teaching is to help students apply what they have learned so as to comprehensively apply various techniques in the training to practical competitions for the purpose of testing specific teaching effect. If they can all outstanding scores in basketball competitions, the first factor is high speed so as to achieve the switch between defense and offence in the fierce competition and fighting. Particularly in high-pace basketball competitions, it is necessary to apply own techniques to rapidly promote the technique action. Teachers should substantially know the distinctive characteristics of basketball competition so as to have the priority during the process of competition teaching method application. They should help learners to skillfully apply technique and should focus on the speed training of attack and defense transition, combine both together to give a full play in real competitions. This teaching method is with competition as the central procedure of teaching. The focus of teaching should not be repeated and boring training of action. It should stress the practicability and interaction of basketball teaching, regard practical application as the most important content. In basketball teaching process, except for organizing learners to join in various competition, it is possible to actively introduce multi-media teaching methods and play some classical basketball completions to guide students to learn the most popular basketball techniques and tactics in the world so as to find out their own shortcomings for improvement and strengthen the effect of basketball classroom teaching.

\section{Some problems need paying attention to when applying competition teaching method in basketball teaching}

Firstly, always adhering to the dominant status of PE teacher, and displaying students' subject status at class do not mean that teachers will lose their control of classroom teaching activities. Teachers should accurately develop their leadership, which is the basic condition to realize learners' subject position. Before taking classes, PE teachers should carefully get prepared to guarantee the real realization of teaching objective. They should reasonably adjust the teaching contents of basketball teaching materials according to learners' specific condition to reasonably arrange the teaching schedule and comprehensively and profoundly research and dissolve basketball teaching materials so as to make the teaching objective clear and maneuverable. During basketball competition, PE teachers should guide and adjust based on students' different conditions by substantially keeping good teaching atmosphere without deviating specific contents of teaching.

Secondly, PE teachers should have a view of overall situation to substantially guarantee learners' security. As basketball competition has high confrontation degree and there exist many safety hidden factors. In those competitions requiring for large body contact and comparison intensity and high danger degree, it is necessary to operate according to competition requirements. Otherwise it will easily cause chaos so as to cause personal injury accidents and affect the basketball teaching activity to be carried out normally. In view of this, it requires for PE teachers to substantially strengthen different protective measures when carrying out teaching activities, and try best to control the amount of exercise. Once any friction between students, PE teachers should resolve rapidly so as to truly 
reduce the mental and physical load of learners so as to guarantee the teaching effect of basketball competitions.

Thirdly, during basketball teaching, it is necessary to strengthen learners' ideological and moral education so that they can truly realize that individual is a member of the team and the success of competition requires for team combat. They should focus on offence but also defense, and cooperate with others during the attack without harming the team interest only considering personal interests. Thus, it is necessary to include ideological and moral education into teaching as an important method for promotion, and combine ideological and moral education with classroom teaching to comprehensively integrate into the whole process of implementing competition teaching method by means of purposeful teaching methods according to learners' practical mindset.

Fourthly, step and integrate into students. When implementing this teaching method, teachers should always play the role of participator to appropriately participate into the completion through the interaction with students so as to deepen mutual understanding and cognition so that learners can learn the techniques and tactics of basketball in a relaxed and happy environment for further improving their basketball techniques and level.

Fifthly, make comprehensive and fair evaluation. At the end of basketball competition, teacher should extract relevant time for comments and summary. They should give fair and equal comments according the practical competition, or it will influence learners' activity and trust on teachers. Based on this, teachers should evaluate students' overall performance and praise students who perform well and care for the team, encourage students who still need to improve and point out points for improvement so as they can progress in the next time.

\section{Conclusion}

To sum up, competition teaching method is an important teaching method in basketball teaching which has dominant advantages compared with traditional teaching methods to improve the quality of basketball teaching and learners' subjective initiative, and cultivate their teamwork cooperation and interpersonal commination. In specific teaching process, PE teachers should focus on continuous innovation and arrange specific contents of teaching scientifically and reasonably, so as to better apply competition teaching methods and to promote better development of basketball teaching and comprehensively improve learners' mental and physical quality.

\section{References}

[1] Sun Zhiwei. Significance of competition teaching method in college basketball teaching, Contemporary Sports Technology, 2014, (34).

[2] Wang Yong, Huang Pingbo, and Wang Limin. Studies on application of competition in basketball teaching, Youth Sports, 2015, (1).

[3] Han Zhiqiang. Effect of competition in college basketball teaching, Reading and Write Periodical, 2015, (1).

[4] Cheng Xinlei. Brief discussion of the effect of competition teaching method in college basketball teaching, Sports World (Scholarly), 2015, (2).

[5] Xiong Hui. Applcication of competition teaching method in college basketball teaching, Contemporary Education Research and Teaching Practice, 2016, (1). 